\title{
Institucionalidade do mercado de câmbio e a política cambial no Brasil *
}

\author{
Pedro Rossi $i^{\text {** }}$
}

\section{Resumo}

Este artigo busca contribuir para análise da política cambial no Brasil a partir de um enfoque centrado na institucionalidade do mercado de câmbio brasileiro. Para isso, primeiramente, descreve-se a operacionalidade desse mercado, separando-o em quatro níveis (mercado à vista, interbancário, de derivativos e offshore) com base em informações oriundas de entrevistas com agentes do mercado de câmbio, como operadores de câmbio do mercado financeiro, agentes da BM\&F, do Banco Central, Tesouro Nacional e da Fazenda. A partir dessa análise, avalia-se como essa institucionalidade condiciona as políticas de câmbio no Brasil (como as intervenções do Banco Central, os controles sobre fluxos de capital, a regulação sobre a posição dos bancos e a taxação sobre as operações de derivativos) e, em particular, como essas políticas impactam a taxa de câmbio a partir da mediação dos canais de arbitragem, da formação de preços futuros e do desincentivo às operações especulativas.

Palavras-chave: Câmbio; Política cambial; Derivativos; Controles de capital.

\section{Abstract \\ Institutionality of the foreign exchange market and exchange rate policy in Brazil}

This paper aims to analyze the exchange rate policy in Brazil from an approach centered on the institutionality of the Brazilian foreign exchange market. For this, it first describes the operation of this market by separating it into four levels (spot, interbank, derivatives and offshore markets) based on interviews' information with agents of the foreign exchange market, as financial currency traders, agents of the BM\&F, Central Bank, Treasury and Finance Ministry. From this analysis, it is evaluated how this institutionality affects exchange policies rate in Brazil (such as Central Bank intervention, capital flows controls, the regulation on banks spot position and the derivative transactions taxes) and, in particular, how these policies impact the exchange rate considering the intermediary channels as the arbitration between spot and future markets, the formation of future prices and the disincentives to speculative operations.

Keywords: Foreign exchange; Exchange rate policy; Derivatives; Capital controls.

JEL F310, G130, O240.

\section{Introdução}

Há algum tempo, a taxa de câmbio tem ocupado o centro do debate econômico brasileiro. Em um cenário de abundância de liquidez internacional, as

\footnotetext{
* Trabalho recebido em 19 de abril de 2012 e aprovado em 8 de fevereiro de 2014. Este artigo é parte da Tese de Doutorado (Rossi, 2012) defendida no Instituto de Economia da Unicamp sob a orientação do professor Ricardo Carneiro.

*** Professor do Instituto de Economia da Universidade Estadual de Campinas (Unicamp. IE), Campinas, SP, Brasil. E-mail: pedrorossi@eco.unicamp.br.
} 
características estruturais da economia brasileira, de alto patamar da taxa de juros, estabilidade política e institucional e crescimento econômico sustentado, fizeram do Brasil um excelente destino para as operações especulativas de carry trade. Diante disso, a política cambial tem assumido um papel cada vez mais ativo na política econômica brasileira.

Desde a crise de 2008, foram utilizadas várias formas de política cambial, como as intervenções no mercado à vista, os swaps cambiais, os leilões de divisas direcionados ao financiamento do comércio exterior, os impostos sobre fluxos financeiros, os leilões de dólar a termo, os impostos sobre margens de garantia para contratos futuros e os impostos sobre o excesso de posição líquida vendida e sobre a redução de posições compradas em derivativos de câmbio. Para entender o efeito dessas políticas é preciso, antes de tudo, se debruçar sobre o mercado de câmbio no Brasil. Questões como a assimetria de liquidez entre os mercados à vista e futuro, o papel dos bancos comerciais na arbitragem entre esses dois mercados, o mercado offshore e o papel da especulação no mercado futuro são algumas das especificidades que devem ser consideradas pelos estudos acerca da taxa de câmbio brasileira, assim como para elaboração de políticas cambiais.

Nesse contexto, este artigo busca contribuir para a análise e a elaboração da política cambial brasileira tendo-se em conta os fatores microeconômicos do mercado de câmbio, como as instituições, os agentes, a regulamentação e os canais de arbitragem entre os diferentes mercados. Parte-se do princípio de que a avaliação das políticas cambiais só é possível quando delimitado o ambiente institucional no qual são aplicadas. Ou seja, dada a complexidade da dinâmica cambial, a análise de política deve ter em conta os vários segmentos dos quais é composto o mercado de câmbio e como essas partes se comunicam. Por exemplo, uma política de controle de fluxo capital não é eficaz ou ineficaz por natureza; ela depende de outros fatores institucionais, como o grau de acesso dos agentes ao mercado de derivativos e a existência de canais de arbitragem livres de custo entre este último mercado e o mercado interbancário. É objetivo deste artigo prover insumos para esse tipo de avaliação.

Para isso, a primeira parte do artigo descreve o mercado de câmbio brasileiro com base em informações oriundas de entrevistas com agentes do mercado de câmbio, como operadores de câmbio do mercado financeiro, agentes da BM\&F, do Banco Central, do Tesouro Nacional e do Ministério da Fazenda $^{1}$. Além disso, faz-se uso da escassa literatura acadêmica que trata da

(1) Para mais detalhes sobre as entrevistas, bem com para acessar os questionários aplicados às mesmas, ver Rossi (2012). 
operacionalidade do mercado de câmbio, como Prates (2009) e Souza e Hoff (2006) para o conjunto do mercado; Garcia e Urban (2004) para o mercado interbancário; Dodd e Griffith-Jones (2007) e Farhi (2010) para o mercado de derivativos no Brasil. A descrição do mercado parte da análise das características do mercado primário e, em seguida, agregam-se os elementos que compõem a totalidade do mercado de câmbio da moeda brasileira: o mercado interbancário, as intervenções do Banco Central, o mercado de derivativos onshore e, por último, o mercado offshore.

Uma vez caracterizada a institucionalidade do mercado de câmbio brasileiro, o artigo explora duas variáveis-chave para a compreensão do impacto das políticas cambiais: o dólar futuro e o cupom cambial. Essas duas variáveis sofrem impactos diretos ou indiretos da política cambial, condicionam a especulação no mercado futuro e a arbitragem entre este último e o mercado à vista. A última parte do artigo discute o impacto de políticas de câmbio no Brasil (como as intervenções do Banco Central, os controles sobre fluxos de capital, a regulação sobre a posição dos bancos e a taxação sobre as operações de derivativos) à luz das características do mercado de câmbio discutidas previamente. Essa análise procura mostrar como o efeito final de cada uma das políticas está condicionado pelo impacto das mesmas nos canais de arbitragem, pelo custo da especulação e pela formação dos preços no mercado futuro.

\section{Institucionalidade do mercado e formação da taxa de câmbio do real}

\subsection{Os fluxos de divisas e o mercado primário}

Uma primeira observação sobre o mercado de câmbio brasileiro é a ausência de contas denominadas em moeda estrangeira, salvo exceções pouco significativas em termos de volume negociado ${ }^{2}$. Dessa forma, a maioria das operações de câmbio é liquidada, na ponta da moeda estrangeira, por meio de transferência entre contas no exterior. A exceção é o câmbio manual, relevante para a conta de viagens internacionais, que implica na circulação física de divisas estrangeiras. Dessa forma, as compras e vendas de dólares no mercado onshore ocorrem, em sua maioria, por movimentações em contas no exterior e, a rigor, não há entradas e saídas significativas de divisas do país, mas uma variação dos ativos e passivos em moedas estrangeiras dos residentes que participam do mercado.

(2) Entre as exceções permitidas estão embaixadas e organismos internacionais e as empresas seguradoras ligadas aos setores do comércio externo. O uso dessas contas em dólar onshore, no entanto, é muito restrito. 
No Brasil, diferentemente de outros países, as operações com divisas estrangeiras devem ser formalizadas em contratos de câmbio e realizadas por intermédio das instituições autorizadas a operar no mercado de câmbio pelo Banco $\mathrm{Central}^{3}$. O conjunto de contratos de câmbio realizados entre residentes e não residentes compõe o mercado primário de câmbio e, em um dado período, esses contratos definem o conceito de fluxo cambial contratado. Essas operações contemplam, por exemplo, a venda de divisas de receitas de exportações, a compra de divisas para importação, a compra e venda de divisas para o turismo ou investimentos no Brasil e no exterior etc.

Seguindo a caracterização de Akyüz (1993), há três graus de abertura financeira: no primeiro, os residentes podem captar recursos (formar passivos) no exterior e os não residentes podem trazer recursos (formar ativos) para o país. No segundo grau de abertura, os residentes podem enviar recursos para o exterior (formar ativos) e os não residentes podem captar recursos no país (formar passivos). Já o terceiro grau de abertura é o da conversibilidade interna da moeda, quando a moeda estrangeira pode ser usada para pagamentos e relações de débito e crédito no âmbito doméstico. A liberalização financeira no Brasil avançou até o segundo grau dessa caracterização ${ }^{4}$, ou seja, não há limites para a movimentação de divisas entre residentes e não residentes. Os primeiros podem captar livremente divisas no exterior assim como converter reais em divisas e enviar os recursos para fora. Contudo, não é permitido o uso da moeda estrangeira para relações de débito e crédito no âmbito doméstico entre residentes, com exceção das instituições autorizadas pelo Banco Central ${ }^{5}$.

Tampouco o não residente está sujeito a restrições quantitativas; a movimentação dos recursos desse agente depende da abertura de uma conta especial: a chamada "conta 2689". Até recentemente, os recursos dessa conta podiam ser movimentados entre diferentes modalidades de aplicações (de investimento em portfolio para investimento direto e vice-versa, ou de empréstimos em investimento etc.) sem a necessidade de um novo contrato de câmbio. Não

(3) As operações de câmbio realizadas pelas instituições autorizadas devem ser formalizadas em contratos de câmbio e registradas no Sisbacen com identificação completa da operação, o que inclui a identificação das partes, a natureza da operação e a taxa de câmbio. O Sisbacen é o sistema de informações do Banco Central, caracterizado por um conjunto de recursos de tecnologia da informação, interligados em rede, utilizado na condução de seus processos de trabalho.

(4) Pode-se dizer que o Brasil não completou o segundo grau de abertura financeira por conta das dificuldades impostas aos não residentes para a formação de passivos.

(5) Biancareli (2010) faz uma análise da evolução da abertura financeira brasileira até 2009, partindo da caracterização de Akyüz (1993).

(6) Em alusão a Resolução do Banco Central 2689, de janeiro de 2000, que permite aplicações dos estrangeiros nos mercados de derivativos, ações e renda fixa sem restrições quanto ao tipo de operação e sem limite de posição. 
havia, portanto, um "controle de informações" sobre o paradeiro do investimento estrangeiro. A partir de 2008, com a introdução do IOF (Imposto sobre operações financeiras) sobre aplicações em renda fixa ${ }^{7}$, exige-se um contrato de câmbio simbólico para a modificação da modalidade do investimento dos estrangeiros e a eventual aplicação do $\mathrm{IOF}^{8}$.

As operações do mercado primário devem passar pela intermediação dos bancos, uma vez que os agentes primários não são autorizados a negociar divisas diretamente entre $\mathrm{si}^{9}$. Ao atender a demanda por liquidez dos agentes primários, os bancos acumulam posições em divisas estrangeiras. A posição de câmbio de um banco pode ser entendida como o resultado líquido de suas operações no mercado de câmbio à vista e para entrega futura (em ambos os casos, com entrega física de moedas), apurado em dólares, acrescido ou diminuído da posição do dia anterior (BCB, 2003). Ela pode ser "comprada", quando as compras acumuladas em moeda estrangeira são maiores do que as vendas, e "vendida", quando o total de compras é menor que o total de vendas, e nivelada, quando há equilíbrio nessa relação. Destaca-se que o acúmulo de posições de câmbio no Brasil é uma prerrogativa dos bancos que só é possível por intermédio de um recurso institucional que consiste em uma linha de negociação de divisas no mercado interbancário internacional que prescinde da contratação de câmbio: as operações de linha ${ }^{10}$.

As operações de linha são canais de financiamento em dólar dos bancos domésticos com bancos no exterior, geralmente sucursais. O saque e o pagamento dessas linhas não envolvem conversão de recursos entre reais e dólares e são as únicas operações de câmbio entre residentes e não residentes que não exigem contrato de câmbio, logo não constam no fluxo cambial. Os recursos captados pelas linhas só alteram a posição de câmbio dos bancos quando são convertidos em reais, ou seja, quando são vendidos no mercado primário ou para o Banco Central (nesses casos, com contrato de câmbio).

Essas operações de linha também são usadas pelos bancos para o envio de recursos ao exterior. Ou seja, quando o banco compra divisas no mercado primário (que impacta negativamente o fluxo cambial e positivamente a posição dos bancos), ele envia os recursos para contas no exterior sem a necessidade de outro

(7) Em 2008, o Decreto 6.391 instituiu a aplicação do IOF de 1,5\% sobre investimento e aplicações de renda fixa. Nos anos seguintes, houve alterações nessa alíquota.

(8) Do ponto de vista contábil, o "contrato simbólico" consiste em uma operação simultânea de câmbio cujo efeito, no balanço de pagamentos, é a saída de recursos pela conta onde originalmente os recursos entraram e uma entrada na nova modalidade de investimento.

(9) "Diversas outras instituições financeiras e não financeiras - como corretoras e distribuidoras, agências de turismo, etc. - estão autorizadas a operar no mercado de câmbio com clientes, porém sem autorização para manter posições em aberto. As corretoras de câmbio desempenham um papel auxiliar, destinado a facilitar as transações no mercado interbancário" (Souza; Hoff, 2006, p. 20)

(10) Também conhecidas no mercado como linha clean ou linha intercompany. 
contrato de câmbio, portanto, sem passar novamente pelo fluxo cambial. Nesse sentido, no que se refere ao câmbio contratado, os bancos podem "vender câmbio" sem antes "comprar câmbio", e vice-versa, e assim acumular posições compradas ou vendidas.

Vale destacar que a separação entre o fluxo cambial e a posição de câmbio dos bancos é uma consequência contábil da existência das operações de linha já que, se não existisse esse canal institucional, toda e qualquer transação bancária internacional exigiria contrato de câmbio e passaria pelo fluxo cambial. Além disso, há implicações práticas decorrentes dessa separação; por exemplo, quando o banco vende dólar no mercado à vista com recursos de linha, seja para o mercado ou para o Banco Central, não há incidência de $\mathrm{IOF}^{11}$.

\subsection{Os estoques de divisas e o mercado interbancário}

Quando um banco vende ou compra divisas além do desejado, ele procura outro banco para ajustar sua posição de câmbio. $\mathrm{O}$ mercado interbancário, ou secundário, descrito detalhadamente em Garcia e Urban (2004), é onde as posições de câmbio dos bancos residentes são niveladas. Ele pode ser descrito como o lócus da negociação do estoque de divisas entre as instituições que podem carregar posições de câmbio. Vale dizer que a posição de câmbio pode ser ajustada no mercado interbancário entre cada banco individualmente, mas não para o agregado do sistema bancário. No Brasil, a maior parte das operações do mercado interbancário ocorre na clearing de câmbio da $\mathrm{BM} \& \mathrm{~F}^{12}$.

No País, não há limites para a posição vendida ou comprada dos bancos. Entretanto, em julho de 2011, o Banco Central instituiu o recolhimento compulsório sobre a posição vendida dos bancos superiores a US\$ 1 bilhão ou, para bancos menores, limites inferiores a esse valor, ponderados pelo patrimônio de referência ${ }^{13}$. Essa medida gerou um ajuste de posição do sistema bancário que resultou na compra líquida de câmbio pelo sistema bancário. Esse tipo de ajuste pode ocorrer tanto de forma passiva, quando os bancos absorvem as divisas de agentes do mercado primário, como por meio de captação direta de recursos no

(11) O fator gerador de IOF é o contrato de câmbio; por isso, segundo informações de entrevistas, haveria dificuldades técnicas para a aplicação do imposto.

(12) O Banco Central não divulga dados sobre o volume das negociações do interbancário, mas informações de entrevistas sustentam que a clearing da BM\&F representa entre 90 a $95 \%$ das operações desse mercado.

(13) Ver Circular 3.548, de julho de 2011. A medida anterior, Circular 3.520, de 06 de janeiro de 2011, estabelecia o valor de US\$ 3 bilhões como limite. O Banco Central também adotou medida que onera a posição comprada dos bancos (acima de US\$ 5 milhões) em 1997, quando o regime cambial brasileiro estava sendo questionado pela queda no montante de reservas e pelas crises no front externo (ver Circular 2.787). Para Garcia e Urban (2004), a restrição à posição comprada dos bancos não surte efeito em tempos de crise, uma vez que é preferível depositar dólares sem remuneração e ganhar com a desvalorização cambial. 
exterior pelos bancos, principalmente via emissão de eurobonds que, diferentemente das operações de linha, são operações do mercado primário, exigem contrato de câmbio e, portanto, aumentam a posição comprada dos bancos e constam no fluxo cambial.

A posição dos bancos, assim como os fluxos de divisas, pode ser extremamente relevante para a formação da taxa de câmbio. Considerando apenas os mercados primário e interbancário de câmbio e descartando a intervenção do Banco Central nesses mercados, a cotação da taxa de câmbio depende de duas variáveis:

1) Do fluxo cambial líquido.

2) Da vontade dos bancos de manter ou variar sua posição cambial.

Ao considerar somente a primeira variável, a taxa de câmbio resulta da interação entre oferta e demanda por divisas decorrentes das relações comerciais e financeiras da economia brasileira com o exterior. Porém, considerando a segunda variável, a vontade dos bancos de variar seu estoque de divisas é um fator relevante na formação da taxa de câmbio. Pode haver situações em que a entrada líquida de dólares é importante, mas o real se deprecia, já que os bancos querem aumentar a posição comprada em dólares. Ou seja, os dólares do mercado são disputados pelos bancos que oferecem preços melhores pela moeda americana para os agentes primários e no interbancário, o que deprecia o real. A situação oposta ocorre quando não há fluxo positivo de divisas, mas os bancos querem se livrar de posições compradas em dólar ou aumentar sua posição vendida. Nesse caso, seguindo raciocínio homólogo, a taxa de câmbio do real se aprecia. O ponto relevante - e por vezes não identificado em análises econômicas - é que o movimento da taxa de câmbio não está necessariamente ligado ao fluxo de câmbio.

Sobre essa questão, há uma analogia possível com a discussão de Keynes (1930) sobre a circulação financeira e as tendências altistas (bull) e baixista (bear). A análise do autor, voltada para qualquer mercado de ativos, põe em relevo a importância dos estoques na determinação do preço dos ativos. Ao trazer essa discussão para o mercado de câmbio brasileiro, destaca-se que o mercado interbancário, apesar de não envolver fluxos efetivos de divisas, sensibiliza a taxa de câmbio. Ou seja, a troca de posição entre os bancos - que implica na negociação dos estoques de divisas -, e não apenas o fluxo de divisas, tem impacto importante na formação da taxa de câmbio brasileira.

No mercado interbancário também ocorrem contratações de câmbio em que o Banco Central está em uma das duas pontas: são as chamadas intervenções do Banco Central. A relação entre as intervenções do Banco Central, a posição dos bancos e o fluxo cambial é dada pela equação (1), onde $\mathrm{FC}_{t}$ é o fluxo cambial contratado no período $t, \mathrm{IBC}_{t}$ são as intervenções do Banco Central no mercado à 
vista no período $t$ decorrentes de compras e vendas no mercado, $\Delta \mathrm{PB}_{t}$ é a variação da posição comprada em dólares dos bancos no período $t$ e $\mathrm{Aj}_{t}$ é uma variável de ajustes $^{14}$.

$$
\text { (1) } \mathrm{FC}_{t}=\mathrm{IBC}_{t}+\Delta \mathrm{PB}_{t}+\mathrm{Aj}_{t}
$$

As compras e vendas do Banco Central são realizadas no mercado interbancário e, portanto, têm impacto direto na posição dos bancos e nas reservas cambiais do Banco Central, mas não passam diretamente pelo fluxo cambial. No limite, o fluxo cambial contratado pode ser zero, mas a posição vendida dos bancos pode aumentar com a venda de dólares dos bancos para o Banco Central. Ou ainda, caso a autoridade monetária compre mais dólares do que o fluxo cambial, por exemplo, a posição vendida dos bancos necessariamente aumentará. Nesse sentido, o acúmulo de posição de câmbio à vista pelos bancos, vendida ou comprada, ocorre de forma passiva e isoladamente, e não representa uma estratégia especulativa por parte dos mesmos:

É importante insistir no ponto acima pois há uma visão difundida, que frequentemente aparece na imprensa especializada, de que os bancos aumentam suas posições compradas quando há uma expectativa de desvalorização cambial. A ação dos bancos, diante de uma expectativa de desvalorização (ou de valorização), se reflete muito mais numa variação de preços (da taxa de câmbio), do que nas suas posições compradas (Souza; Hoff, 2006, p. 23).

Vale atentar para o papel dos bancos no mercado de câmbio. Por um lado eles assumem uma posição passiva ao atender a demanda e a oferta de divisas estrangeiras no mercado primário, tendo sua posição de câmbio agregada alterada pela decisão dos clientes. Por outro, têm um papel fundamental na determinação da taxa de câmbio, uma vez que precificam a moeda de acordo com a estratégia referente à sua posição de câmbio. Ou seja, o ajuste de preço (leia-se da taxa de câmbio) é um instrumento dos bancos para tentar dissuadir (incentivar) clientes e outros bancos a efetuarem uma operação de compra (venda) indesejável (desejável). Já o significado da posição de câmbio à vista deve ser analisado em conjunto com a posição de câmbio no mercado de derivativos.

(14) Sobre os ajustes, essa informação obtida em entrevista é esclarecedora: "os ajustes referem-se a alguma operação de câmbio desfeita. Quando um exportador contrata câmbio hoje para embarcar a mercadoria em um ano, a posição de câmbio da instituição é afetada hoje e a estatística de fluxo é publicada hoje. Daqui um ano, o exportador informa que desistiu da operação e pede ao banco que cancele o contrato. O contrato é cancelado, e o banco registra essa alteração no Banco Central, requisitando o ajuste da posição. A posição é ajustada, mas não há revisão no fluxo de um ano atrás. Resultado: a posição variou, mas sem alteração nos fluxos, esse é um ajuste. Diariamente, centenas de contratos de exportação, importação e financeiro são cancelados ou alterados. Muitas vezes, as alterações nas entradas e saídas se compensam, mas isso não é uma regra." 


\subsection{O mercado de derivativos de câmbio}

O mercado de derivativos de câmbio tem a importante função de fornecer hedge para os agentes do sistema. Para o setor bancário, isso permite o acúmulo de posições à vista sem exposição à variação cambial. Os bancos com posição vendida (comprada) em dólar no mercado à vista realizam operações de compra (venda) no mercado futuro em montante equivalente e, dessa forma, eliminam o risco de variação da taxa de câmbio 15 . O chamado "dólar casado" é uma operação em que o banco assume uma posição no mercado à vista e simultaneamente a posição contrária no mercado futuro, gerando o hedge cambial. Dadas as restrições das negociações no mercado à vista, muitos bancos preferem fazer o hedge no mercado futuro em vez de ajustar posição no mercado interbancário:

Os participantes do mercado interbancário de câmbio passaram a privilegiar o mercado de derivativos para realizar suas operações indexadas à taxa de câmbio, deixando o mercado interbancário apenas para suprir suas necessidades em moeda estrangeira, para liquidar operações do mercado primário (Garcia; Urban, 2004, p. 12).

Há duas características particulares no mercado de derivativos de câmbio brasileiro. A primeira é que, ao contrário de outros países, os contratos efetuados no mercado de balcão devem ser registrados em instituições autorizadas, como a Cetip e a BM\&F. Sem o registro, essas operações não têm validade legal e, portanto, não podem ser questionadas na justiça (Dodd; Griffith-Jones, 2007) ${ }^{16}$. Já a segunda característica é o tamanho do mercado futuro, que é desproporcionalmente maior que o mercado à vista quando comparado a outros países.

Um dos principais motivos para essa assimetria de liquidez é uma assimetria regulatória entre esses mesmos mercados. Conforme discutido, a formação de posições no mercado de câmbio à vista é restrita a instituições bancárias e corretoras especializadas, que devem ter autorização do Conselho Monetário Nacional e suas operações formalizadas em contratos de câmbio e registradas no Sisbacen ${ }^{17}$. Já no mercado futuro da BM\&F, qualquer agente pode formar posições abertas em dólar futuro, desde que cadastrado no sistema dessa instituição. As menores exigências regulatórias e a facilidade de acesso condicionam a atuação dos agentes do mercado de câmbio e a atraem investidores estrangeiros para a negociação da moeda brasileira no mercado futuro. Para Prates

(15) O mercado de derivativos não se resume ao mercado futuro. O termo "futuro" será empregado no artigo pelo fato de a ampla maioria das operações de derivativos de câmbio no Brasil ser realizada nesse mercado.

(16) "Mais recentemente, a Resolução n. 3.824, de 16 de dezembro de 2009, do CMN, estendeu a obrigatoriedade de registro pelas instituições financeiras aos derivativos contratados no exterior" (BCB, 2010, p. 34).

(17) Em 20 de setembro de 2013, 190 instituições estavam autorizadas a operar no mercado de câmbio. 
(2009), a existência de um mercado futuro líquido de reais atrai investidores de ativos com características similares às da moeda brasileira:

Esse número recorde também está relacionado ao fato de alguns investidores globais utilizarem esses contratos como uma proxy de derivativos de moedas emergentes, que são altamente correlacionadas ao real (como a lira turca e o rand sul-africano), mas não possuem mercados de derivativos organizados líquidos e profundos (Prates, 2009, p. 267).

No mercado futuro não há contratos de câmbio, uma vez que operações são liquidadas em reais, e, portanto, não há movimentação de divisas. Com isso, a legislação cambial que condiciona a negociação de divisas no mercado à vista não se aplica a esse mercado. Em 2000, os não residentes passaram a ter permissão para atuar no mercado futuro da BM\&F. Desde então, a atuação desses agentes tem sido importante no volume financeiro de dólar futuro. Entre 2006 e 2011, os estrangeiros representaram a categoria de agente que mais negociou contratos de dólar futuro, juntamente com os bancos domésticos. Para Kaltenbrunner (2010), a atuação dos hedge funds estrangeiros tem um papel de destaque nesse mercado:

A large share of those interviewed declared that foreign institutional investors, primarily hedge funds, have become the most important investor group in driving exchange-rate dynamics in the Brazilian market (Kaltenbrunner, 2010, p. 313).

Para os estrangeiros, a operação na BM\&F depende da abertura de uma conta 2689 para a constituição de margens de garantia para as operações ${ }^{18}$. Os recursos trazidos pelos estrangeiros para essa conta estão sujeitos a contrato de câmbio e incidência de IOF. Como forma de contornar a incidência de impostos, tornou-se comum a abertura da conta e a tomada de empréstimos em reais com bancos domésticos ou o aluguel de títulos que servem como garantia na BM\&F junto aos bancos ${ }^{19}$. No que se refere aos limites de exposição, eles não existem para os estrangeiros e residentes, com exceção dos bancos, enquadrados pelo acordo de Basileia II. Para estes últimos, a exposição cambial - medida pela soma líquida dos ativos sujeitos à variação cambial - é restrita a 5\% do patrimônio de referência ${ }^{20}$.

(18) A margem teórica máxima para um contrato de dólar futuro com vencimento em um mês foi de $20 \%$ em 2 de julho de 2011. Segundo a BM\&F, nessa mesma data, a composição das garantias depositadas para derivativos em geral era de $91 \%$ de títulos públicos federais, $4 \%$ de ações, $2,7 \%$ de cartas de fiança e $0,8 \%$ em dinheiro. Outros ativos são aceitos como margem, entre eles o ouro, títulos privados e o dólar em espécie. Sobre a forma de operação da BM\&F, ver anexo.

(19) A Resolução 3910 de março de 2011 restringiu esse tipo de estratégia.

(20) Diferentemente da posição cambial, a exposição cambial mede os ativos e passivos à vista e as obrigações a termo. Os bancos informam diariamente ao Banco Central sua exposição cambial em relação ao patrimônio de referência. A Circular 3.389 estabelece o limite de exposição, e a Circular 3.444 regulamenta o cálculo do patrimônio de referência. 
A ligação entre os mercados à vista e de derivativos de câmbio ocorre pela arbitragem realizada pelos bancos ${ }^{21}$. $\mathrm{O}$ excesso de oferta de dólares no mercado à vista (futuro) leva as instituições a comprarem dólares nesse mercado e venderem dólares no mercado futuro (à vista). O resultado da operação é um ganho sem risco cambial e um ajuste de preços nos dois mercados. Vale frisar que a operação de arbitragem não configura uma aposta direcional na moeda. Essa arbitragem se dá em torno da equação da paridade coberta de juros. A seção 2 retoma e detalha esse tipo de operação.

Há uma visão difundida entre os operadores de mesa de câmbio do mercado financeiro de que a taxa de câmbio se forma primeiro no mercado futuro e é transmitida por arbitragem para o mercado à vista. Esse fato é tomado como "intuitivo", uma vez que a liquidez se concentra nesse mercado e, por conta do mercado, toma a taxa futura como referência para a cotação dos demais mercados $^{22}$. Estatisticamente, há inúmeras dificuldades em comprovar essa tese, entre elas a velocidade em que circula a informação nesses mercados, o que exige uma base de dados de altíssima frequência (horas, minutos).

O trabalho de Ventura e Garcia (2009) teve acesso a uma base de dados desse tipo e concluiu que a cotação da taxa de câmbio se forma primeiro no mercado futuro, sendo então transmitida, por arbitragem, para o mercado à vista. Os autores usaram dados de propostas de compra e venda no mercado de câmbio interbancário e futuro da BM\&F e identificam causalidade, no sentido de Granger, com defasagens de 10 minutos. Outros autores sustentam a posição de que a taxa de câmbio se forma no futuro, como Franco (2000) e Dodd e Griffith-Jones (2007); estes últimos também argumentam com base em entrevistas.

\subsection{0 mercado offshore de reais}

O mercado de reais offshore consiste no espaço de negociação de reais entre não residentes em jurisdição estrangeira ${ }^{23}$. Esse mercado possui restrições estruturais dada a inconversibilidade da moeda brasileira ${ }^{24}$. Essa condição faz com

(21) Esses agentes são responsáveis pela arbitragem entre esses dois mercados devido ao acesso privilegiado às taxas de financiamento do interbancário nacional e internacional, caracterizadas por serem as mais baixas do mercado.

(22) Sobre a preponderância do mercado futuro, reproduz-se o argumento de um entrevistado: "uma manifestação explícita de que o mercado à vista é guiado pelo mercado futuro ocorre quando há feriado na BM\&F. Nessas ocasiões a cotação à vista fica desnorteada, sem referências".

(23) Nota-se que o conceito de mercado offshore empregado não se define pelo parâmetro geográfico. Os residentes no País que operam no exterior devem obedecer às prescrições da jurisdição brasileira. No caso de uma operação de NDF (Non Deliverable Forward) no exterior entre um residente e um não residente, essa deve ser registrada em um órgão competente e, a rigor, consiste em uma operação onshore.

(24) A exemplo de Carneiro (2008), considera-se como inconversibilidade o não desempenho das funções da moeda no âmbito internacional. Na prática, refere-se aqui à inexistência do uso da moeda brasileira como meio de pagamento que liquida contratos offshore. 
que os reais negociados no exterior sejam liquidados em moeda estrangeira, logo não há clearing em reais de contratos de câmbio fora do Brasil que exerça influência direta sobre o mercado de câmbio à vista. Dito isso, vale reforçar que a formação da taxa de câmbio à vista do real, diferentemente de moedas centrais do sistema, é um fenômeno exclusivamente onshore. Entretanto, isso não isenta o mercado offshore de reais de influência importante na formação da taxa de câmbio futura.

Os mercados offshore não existem isoladamente; há instituições que operam nesse mercado e que mantêm vínculos constantes com o mercado onshore. A influência desse mercado na formação da taxa de câmbio depende do balanço de operações vendidas e compradas realizadas nessa jurisdição. Como propõem He e McCauley (2010), é importante distinguir o caráter simétrico ou assimétrico do uso de uma moeda offshore. No uso simétrico, os agentes comprados e vendidos em uma moeda se neutralizam, e não há pressão desse mercado sobre a taxa de câmbio onshore. Já no uso assimétrico, o mercado offshore é sistematicamente mais usado para uma das pontas da operação: vendida ou comprada. Neste último caso, as instituições que operam simultaneamente nos dois mercados ajustam suas posições de câmbio no mercado onshore e, com isso, transmitem a pressão compradora ou vendedora para esse mercado. No caso brasileiro, essas posições são cobertas, fundamentalmente, na BM\&F.

Para tornar mais claro o argumento, cabe uma ilustração da forma de operação de um banco offshore. Esse oferece um fundo com rendimento atrelado à moeda brasileira, ou um contrato de NDF (Non Deliverable Forward) em reais, a um cliente que fica vendido em dólares e comprado em reais enquanto o banco assume a ponta contrária. Logo, o cliente aufere diferencial de juros e ganha com a apreciação da moeda brasileira enquanto o banco paga o diferencial de juros e ganha com a depreciação do real. Para fazer hedge dessa operação, o banco recorre ao mercado onshore e vende dólares futuros na BM\&F. A predominância de agentes com posições vendidas em reais no mercado offshore leva, portanto, a ajustes de posições no mercado onshore e transmite pressões para apreciação da taxa de câmbio do real.

Os mercados de câmbio onshore e offshore são arbitrados de acordo com distorções entre as curvas de juros do real nos dois mercados. A curva de juros do real offshore tende a estar abaixo da curva onshore, o que significa que o real é mais caro fora que no Brasil. O motivo para tal são os custos e riscos que envolvem a operação, como os impostos e o risco de fronteira. Os aumentos de IOF, que encarecem as captações externas, assim como o aumento do risco país tendem a encarecer o real offshore, reduzir os juros das aplicações em reais e, assim, desestimular a demanda por posições vendidas em reais. 


\section{0 cupom cambial e a formação dos preços futuros}

A formação de preços no mercado de derivativos é um tema tratado preponderantemente pela literatura de finanças com um enfoque microeconômico, e o tratamento macro desses preços é relativamente ausente nessa literatura. Contudo, a dinâmica desses preços é fundamental para se entender o impacto das políticas cambiais sobre os diferentes mercados e sobre a formação da taxa de câmbio. Nesse sentido, esta seção propõe desenvolver dois conceitos básicos para discussão de política cambial: o dólar futuro e o cupom cambial.

Os preços futuros, além de riscos e expectativas, expressam condições de arbitragem entre diferentes mercados. O preço do dólar futuro, por exemplo, não é o preço esperado do dólar no futuro ${ }^{25}$. Se o dólar futuro fosse efetivamente um previsor adequado do dólar spot no futuro, o mercado estaria não somente errando, como deveria errar sistematicamente e na mesma direção (Garcia, 1997). Isso porque o dólar futuro é dado por uma relação de arbitragem que envolve variáveis conhecidas no presente, enquanto que a previsão da cotação do dólar no futuro é dada pelas expectativas dos agentes. Nesse sentido, os contratos futuros não são bons previsores dos preços no futuro. No caso brasileiro, o dólar futuro está sistematicamente acima do dólar à vista devido ao diferencial entre os juros brasileiros e os juros externos.

Do ponto de vista teórico a determinação da taxa de câmbio futura deve respeitar a paridade coberta da taxa de juros (CIP). A CIP propõe uma relação entre variáveis conhecidas no presente. São elas: a taxa de câmbio spot $\left(e_{s}\right)$, a taxa de câmbio no mercado futuro $\left(e_{f}\right)$ e as taxas de juros internacional e doméstica $i^{*}$ e $i^{d}$.

$$
\text { (1) } e_{f}=e_{s}\left(1+i^{d}\right) /\left(1+i^{*}\right)
$$

De acordo com essa equação, a taxa de câmbio futura é a taxa de câmbio spot acrescida de uma taxa correspondente ao diferencial entre as taxas de juros da moeda doméstica e da moeda internacional. Essa diferença entre as taxas de câmbio à vista e futura é denominada de forward premium quando, como no caso brasileiro, a taxa futura é maior do que a taxa de câmbio à vista, ou forward discount quando ocorre o inverso. Os desequilíbrios dessa equação tendem a ser ajustados pela arbitragem. Considerando as taxas de juros como variáveis exógenas, a partir do desequilíbrio inicial ilustrado pela equação (2), sucedem-se as seguintes operações:

$$
\text { (2) } e_{f}<e_{s}\left(1+i^{d}\right) /\left(1+i^{*}\right)
$$

a) Os agentes do mercado tomam empréstimos no exterior a juros $\left(i^{*}\right)$, trocam as divisas por moeda doméstica no mercado à vista e aplicam os recursos em juros domésticos $\left(i^{d}\right)$. Esse tipo de operação, ceteris paribus, provoca uma apreciação da moeda doméstica $\left(\downarrow e_{s}\right)$.

(25) A análise de Keynes (1924) foi pioneira ao tratar desse aspecto. 
b) Simultaneamente à primeira operação, os agentes compram divisas estrangeiras no mercado futuro, garantindo a cobertura cambial do passivo externo $^{26}$. Esse tipo de operação, ceteris paribus, gera uma depreciação da moeda no mercado futuro $\left(\uparrow e_{f}\right)$.

Essa arbitragem tende a equilibrar os preços da taxa de câmbio à vista e futura, e fazer valer a equação da paridade coberta de juros.

No mercado de câmbio brasileiro, a equação da paridade coberta que serve de referência para a arbitragem dos agentes se apresenta conforme os parâmetros da equação (3).

$$
\text { (3) dólar futuro } t=\text { dólarspot }_{t} * \frac{(1+\text { taxa pré })}{(1+\text { cupomcambial })}
$$

A taxa de juros de referência para aplicações em reais é uma taxa prefixada com rentabilidade dada pelas aplicações de DI. Já o cupom cambial pode ser interpretado como uma taxa de juros que remunera os dólares onshore ${ }^{27}$. A equação (3) está sempre em equilíbrio; uma vez que o cupom é uma variável endógena a essa, ele deriva diretamente da relação entre as outras variáveis e se ajusta de forma a manter a igualdade da mesma. Não obstante, o cupom cambial é a variável relevante para o cálculo para arbitragem. Quando o cupom cambial difere do custo de captação externa, há oportunidades para arbitragem nas seguintes condições:

a) cupom cambial $>$ custo de captação externa ${ }^{28}$.

$\rightarrow$ Há incentivos para tomar empréstimos no exterior e aplicar os recursos no cupom cambial.

b) cupom < custo de captação externa

$\rightarrow$ Há incentivos para tomar empréstimos no mercado doméstico e aplicar os recursos no exterior.

O resultado da arbitragem tende a alterar os parâmetros da equação (3), o dólar futuro e o dólar à vista, que, por sua vez, equilibram o cupom cambial com os juros externos mais os custos adicionais. Já o retorno de uma operação de compra

(26) Essas transações devem ocorrer simultaneamente para evitar exposição ao risco de mercado, ou seja, o risco de os preços se alterarem antes das transações se completarem.

(27) O cupom cambial é usualmente definido como a diferença entre a taxa de juros interna e a expectativa de depreciação da taxa de câmbio do país. Essa definição só é verdadeira se for válida a paridade descoberta de juros; em outras palavras, se for aceito que o diferencial de juros entre aplicações em reais e em dólares traz embutido uma expectativa dos agentes quanto à depreciação da moeda brasileira. Nesse caso, a cotação do dólar futuro seria um bom previsor da cotação do real no futuro. Contudo, é extensa a literatura econômica que mostra que essa paridade não se verifica. A violação da paridade descoberta de juros foi batizada de forward premium puzzle. Sobre a literatura que trata desse assunto, ver Sarno e Taylor (2006).

(28) A referência do mercado brasileiro para os juros externos é a libor, e os custos adicionais são referentes aos spreads de riscos que variam de acordo com os agentes e outros custos operacionais, como os impostos sobre operações financeiras (IOF). 
ou venda de dólar futuro na BM\&F depende de duas variáveis: o preço pago pela taxa de câmbio futura no dia da contratação $(t)$ e a cotação da taxa de câmbio à vista no dia do vencimento do contrato de câmbio futuro $(t+1)$ :

$$
\text { (4) Retorno: } \frac{\text { dólarfuturo }}{\text { dólarspot }_{t+1}}
$$

Para aquele que vendeu dólar futuro, haverá ganho se dólar futuro ${ }_{t}>$ dólar spot $_{(t+1)}$, uma vez que ele estará vendendo em $t+1$ a uma taxa mais cara do que o câmbio do dia. Já para o agente que está comprado em dólar futuro, haverá ganho se dólar futuro ${ }_{t}<$ dólar spot $_{(t+1)}$, uma vez que ele está comprando em $t+1$ a uma taxa mais barata do que o câmbio do dia. O resultado da operação pode ser decomposto ao considerar as equações (3) e (4):

$$
\text { (5) Retorno: } \frac{\text { dólarspot }_{\mathrm{t}}}{\text { dólarspot }_{t+1}} * \frac{\left(1+{\text { Taxa Pré })_{\mathrm{t}}}\right.}{\left(1+{\text { cupomcambial })_{\mathrm{t}}}\right.}
$$

Nessa equação, as taxas de juros são conhecidas ex ante e podem ser consideradas como custo ou ganhos de cada uma das pontas da operação, enquanto a variação cambial é uma variável ex post. Nesse sentido, a ponta vendida em dólar futuro tem como custo o cupom cambial e, como ganho, a taxa prefixada, enquanto a ponta comprada em dólar futuro tem como custo a taxa prefixada e como ganho o cupom cambial. O resultado final da operação depende do resultado do primeiro termo da equação, isto é, da variação cambial. A ponta vendida ganha com a apreciação cambial e a ponta comprada com a depreciação cambial. O Quadro 1 apresenta esses resultados.

Quadro 1

Resultado estilizado de uma operação de dólar futuro

\begin{tabular}{|c|c|}
\hline Venda de dólar futuro & Compra de dólar futuro \\
\hline Ganha taxa pré & Paga taxa pré \\
Paga cupom cambial & Ganha cupom cambial \\
Ganha apreciação cambial & Paga apreciação cambial \\
\hline
\end{tabular}

Fonte: Elaboração própria.

Dois pontos devem ser destacados dessa análise, o primeiro é que quanto mais alto o cupom cambial, mais próximas estão as taxas de câmbio futuras e à vista, e menor o incentivo para o carry trade no mercado futuro ${ }^{29}$. No limite, uma alta do cupom pode neutralizar o diferencial de juros eliminando os incentivos para o carry trade. $\mathrm{O}$ segundo ponto relevante é que o resultado de uma operação de

(29) Conforme definido por Gagnon e Chaboud (2007) o carry trade divide-se em duas categorias: "canonical carry trade" e "derivatives carry trade". No primeiro caso, a operação de carry trade é montada tomando empréstimos na moeda de baixo juros e aplicando em ativos denominados na moeda de alto juros, enquanto, no segundo, pela formação de posição vendida na moeda de baixos juros e comprada na moeda de altos juros no mercado de derivativos. 
venda de dólar futuro é equivalente a uma operação de venda de dólar à vista e aplicação em juros domésticos quando os mercados à vista e futuro estão perfeitamente arbitrados. Nesse caso, o cupom é igual ao custo de captação externa do agente. Por exemplo, quando um agente toma recursos no exterior e aplica diretamente esses recursos em DI, ele terá um resultado equivalente à venda de dólar futuro apresentado no Quadro 1; entretanto, o custo a ser pago não é o cupom, mas o custo de captação externa. Da mesma forma, quando um agente toma emprestado em reais e aplica no exterior ele terá um resultado equivalente à compra de dólar futuro apresentado no Quadro 1, embora o rendimento auferido não seja o cupom, mas os juros internacionais menos o custo de envio dos recursos.

\section{Política cambial no Brasil}

\subsection{Intervenções do Banco Central}

As intervenções do Banco Central, por leilões de compra ou venda de dólares, ocorrem no mercado interbancário de dólares e têm efeito sobre a formação da taxa de câmbio ao alterar a liquidez nesse mercado. O Banco Central é, portanto, um player importante com capacidade de formar preço no mercado interbancário. Há, contudo, uma importante consideração a ser feita sobre essa política no que se refere ao seu impacto sobre o cupom cambial.

Ao intervir no mercado à vista, através de um leilão de compra de dólares, ceteris paribus, a taxa de câmbio à vista se deprecia e se aproxima da cotação da taxa de câmbio futura, o que aumenta o cupom cambial, conforme tratado na seção anterior. Nesse caso, pode-se dizer que, ao retirar liquidez do mercado primário no curtíssimo prazo, o Banco Central também aumenta o prêmio para a reposição dessa liquidez pelo mercado. Com o cupom cambial mais alto, os bancos captam recursos via operações de linha e vendem esses recursos para o Banco Central em uma operação típica de arbitragem ${ }^{30}$. Dessa forma, a intervenção pode incentivar a "entrada" de mais dólares. Se o Banco Central comprar o equivalente ao fluxo cambial, não há motivos para aumentar o cupom cambial, uma vez que se mantém inalterada a condição de liquidez do mercado à vista. No entanto, se a compra for acima do fluxo cambial, as condições do mercado se alteram, e pode haver pressão sobre o cupom cambial.

Uma forma de equacionar esse problema é a intervenção via leilões de swaps reversos. O efeito do swap reverso é de "amenizar" o cupom cambial, pois pressiona pela depreciação da taxa de câmbio futura, o que inibe a arbitragem dos

(30) Dada a operacionalidade do leilão de divisas do Banco Central, os bancos comerciais vendem as divisas ao Banco Central e têm dois dias para entregar os recursos, que podem ser captados por operações de linha junto a uma filial desse banco no exterior. 
bancos $^{31}$. Os swaps reversos, registrados na BM\&F, são equivalentes à compra de dólar futuro. Assim como os contratos futuros, os swaps também oferecem ajustes diários, no entanto, diferentemente desses, não há contraparte central, e os contratos são customizados no que se refere aos prazos de vencimento e aos lotes. Como exemplo, o Banco Central pode realizar um swap de US\$ 1 bilhão dividido em três lotes que vencem em datas diferentes.

Os leilões a termo, introduzidos pelo Banco Central em 2011 têm um propósito um pouco distinto dos swaps. Esses envolvem entrega física de divisa e são úteis quando, por exemplo, uma grande empresa tem uma quantia muito grande de recursos a ser internalizada em uma data futura. Nesse contexto, o leilão de compra de dólares a termo cumpre o papel de evitar que uma grande quantia de dólares altere em demasiado a liquidez do mercado de câmbio.

Outra questão associada à política de intervenções no mercado de câmbio é sua estratégia de operacionalização. As intervenções - em intervalos constantes e valores previsíveis pelo mercado - voltadas para a redução da volatilidade cambial podem ser extremamente favoráveis à especulação no mercado de câmbio. Isso porque a estabilidade cambial em um país com taxa de juros acima do padrão internacional estimula as operações de carry trade. $\mathrm{O}$ caráter especulativo da operação é amenizado pela maior previsibilidade da taxa de câmbio e, nesse sentido, os ganhos da operação são menos incertos. Decorre daí que a estabilidade pode gerar apreciação, uma vez que incentiva os agentes a investirem em reais para obter ganhos com o diferencial de juros.

Já a política de intervenção, que ocorre sem anúncio e de forma errática, perturba as referências dos agentes que estão expostos à variação cambial. Ao atuar dessa forma, o Banco Central induz os especuladores a perdas e inibe futuros movimentos especulativos. Há, portanto, dois efeitos das intervenções que devem ser evitados pelo Banco Central: 1) o aumento do cupom cambial (sem aumentar o custo de captação dos agentes); 2) gerar demasiada previsibilidade no mercado.

\subsection{Controles de fluxos de capitais}

Como descrito neste trabalho, o Banco Central tem controle sobre as operações de câmbio dos agentes primários a partir dos contratos de câmbio sobre os quais, tecnicamente, é aplicado o IOF. Esse controle se estende para as operações que não envolvem câmbio de divisas, mas que mudam a natureza dos

(31) No limite, uma intervenção via swap reverso pode colocar o cupom cambial abaixo da taxa de juros externa, o que incentiva a arbitragem no sentido oposto ao que vem sendo discutido: os bancos captam no mercado doméstico e aplicam os recursos no exterior. 
investimentos externos ${ }^{32}$. Dessa forma, do ponto de vista técnico, não há dificuldades para a aplicação desse tipo de controle de capital. No entanto, quando há fluxos de capitais que não estão sujeitos ao imposto, a entrada de recursos externos pode ser desviada para esses canais, como os investimentos diretos. Contudo, a captação de recursos por essa via deve ponderar algumas restrições relacionadas à natureza do investimento, uma vez que as captações por investimento direto têm a característica de modificar a estrutura de capital de uma empresa $^{33}$.

Alguns fluxos classificados como comerciais, como as antecipações de receitas de exportações, também oferecem formas de carry trade. Existem duas formas de antecipação do valor das exportações no Brasil: o ACC (Adiantamentos sobre Contratos de Câmbio) e o PA (Pagamento Antecipado de Exportação). O primeiro usa o sistema bancário doméstico como intermediário, e o segundo é uma relação de crédito direta com um não residente (banco estrangeiro ou importador), e ambos estão sujeitos à exportação física de mercadorias dentro de um prazo estipulado. Esta última condição deu origem a um mercado secundário de performances de exportação que negocia o direito de exportação de produtos prontos para serem exportados (Rossi; Prates, 2009). Esse mercado permite, em tese, que agentes não exportadores façam uso das linhas de crédito à exportação ${ }^{34}$. Nesse sentido, apesar de a finalidade desses instrumentos ser financiar a produção e o processo de comercialização de produtos para exportação, esses recursos podem ser desviados para uma aplicação de renda fixa, caracterizando, assim, uma estratégia de carry trade que escapa aos controles de fluxo de capital.

Em condições normais os controles de capitais também afetam a operação do mercado futuro. O imposto sobre fluxo de capital, ao aumentar o custo de captação externo, pode modificar os parâmetros do mercado futuro, reduzindo o forward premium e aumentando o cupom cambial, como desenvolvido na seção 2. Quando o custo do imposto é incorporado ao cupom cambial, as operações de venda de dólar futuro ficam mais custosas, logo há um desincentivo à especulação no mercado futuro. Entretanto, os controles de capitais podem não afetar a

(32) Como tratado na seção 1, para a modificação da modalidade do investimento dos estrangeiros e a eventual aplicação do IOF é realizado um "contrato de câmbio simbólico".

(33) Os empréstimos intercompanhia que constam no balanço de pagamento na rubrica do investimento direto estão sujeitos a IOF. Esses são uma categoria estatística do Banco Central e não existem como categoria de contrato de câmbio. Do ponto de vista legal e normativo, trata-se de contratos de empréstimos em que ambas as partes são a mesma empresa. Essa categoria não existe para bancos.

(34) "Por outro lado, as condições de funcionamento do mecanismo de ACC/ACE permitem a compra de performance de exportação entre companhias, e isso tem atraído a demanda de empresas que não operam no comércio exterior, ocasionando um desvio considerável de recursos para atividades não-exportadoras." (Blumenschein; Leon, 2002, p. 189). 
atividade no mercado futuro, uma vez que atuam apenas sobre o fluxo cambial. Como mostrado na seção 1, as operações de linha do sistema bancário prescindem de contrato de câmbio e não estão sujeitas a IOF. Dessa forma, quando há canais de arbitragem livres, um ciclo de apreciação com origem no mercado futuro fica isento da influência dos controles. Nesse contexto, medidas de controle de capital devem ser articuladas com outras medidas regulatórias ${ }^{35}$.

\subsection{Medidas regulatórias}

Há diversas medidas regulatórias que podem ser aplicadas dependendo do grau de controle que o Governo deseja ter sobre o mercado de câmbio. Entre elas estão aquelas associadas à formação de posição pelos bancos e aquelas direcionadas ao mercado de derivativos. Sobre o primeiro grupo, deve-se ter em conta o papel dos bancos de arbitrador entre os mercados à vista e futuro. Essa arbitragem não é responsável pela formação de tendências na taxa de câmbio, mas é parte indispensável da transmissão das tendências formadas em um dos mercados.

O canal de captação dos bancos para essa arbitragem são as operações de linha que, como visto, estão isentas de contratos de câmbio e de IOF. A taxação dessas operações exigiria mudanças na institucionalidade do mercado. Um primeiro problema, de natureza técnica, é a taxação de operações que prescindem de contrato de câmbio ${ }^{36}$. Outro problema, de natureza econômica, é que grande parte das operações de linha é usada para o financiamento do comércio exterior por meio de operações de adiantamento de contrato de câmbio (ACC).

O recurso usado pelo Banco Central em 2011 para conter as captações via operações de linha foi a oneração do excesso de posições vendidas dos bancos ${ }^{37}$. Há dois pontos importantes nessa medida. Primeiro, a oneração sobre as posições vendidas acima de determinado nível eleva o custo de captação dos bancos, o que aumenta o cupom cambial. Nesse caso, ela também onera a especulação no mercado futuro. O segundo ponto é que a redução desse limite pode ser uma política extremamente eficiente para, no curto prazo, afetar a taxa de câmbio. Quando os bancos estão operando no limite de sua posição vendida, uma

(35) Outras questões podem ser levantadas a respeito dos controles de capitais. Uma delas é que esse pode ter um efeito inicial maior, uma vez que tem impacto sobre as expectativas dos agentes. Esse efeito tende a se dissipar à medida que o mercado se adapta às novas condições. Outro ponto, não menos relevante, é que os impostos sobre fluxos de capitais podem levar parte das operações de renda variável para o exterior. Mas vale notar que, quando de uma emissão primária de ações, se o objetivo da firma for de financiamento das atividades em âmbito doméstico, essa terá que pagar o imposto quando internalizar os recursos.

(36) O fator gerador de IOF é o contrato de câmbio, por isso, segundo informações de entrevistas, haveria dificuldades técnicas para a aplicação do imposto.

(37) Ver Circular 3.520. 
redução desse limite gera uma corrida ao mercado para a compra de dólares ou de captações no exterior, com o mesmo propósito.

A regulação sobre o mercado de derivativos é tema que exige uma reflexão mais aprofundada do que a que está aqui proposta, contudo vale destacar o impacto de algumas medidas recentes adotadas no Brasil. Em 2010 e 2011, o Governo atuou de duas formas sobre o mercado de derivativos: através de imposto sobre margem na BM\&F e sobre a posição vendida dos agentes. Em 2010, o Governo instituiu um IOF de $6 \%$ para a composição de margem na BM\&F pelos investidores estrangeiros ${ }^{38}$. Esse tipo de imposto tem o efeito de onerar as operações em mercado futuro para os estrangeiros, mas também pode promover uma migração das operações de bolsa para o ambiente de balcão.

Em julho de 2011, através da Medida Provisória 539, o Governo ampliou as possibilidades de intervenção no mercado de derivativos. A partir de então, ficou possibilitada a determinação de depósitos sobre os valores nocionais dos contratos, fixar limites, prazos e outras condições sobre as negociações dos contratos. Além disso, instituiu-se um imposto de $1 \%$ sobre o valor nocional das operações que resultem em aumento da exposição líquida vendida de um agente ${ }^{39}$. Essa medida impõe alguns desafios técnicos, uma vez que nenhuma instituição do Governo tem acesso às posições dos agentes na $\mathrm{BM} \& \mathrm{~F}$ ou no mercado de balcão. Ou seja, a tarefa de coleta do IOF fica delegada às instituições do mercado, nomeadamente à $\mathrm{BM} \& \mathrm{~F}$ e à Cetip.

Uma vez vencidos os entraves técnicos, há inicialmente dois efeitos dessa medida. O primeiro, de caráter regulatório, é permitir ao Governo um melhor monitoramento do mercado e uma maior capacidade de avaliação dos riscos do sistema, uma vez que a exposição cambial dos agentes é uma variável importante para dimensionar os riscos financeiros decorrentes do descasamento de moedas. $\mathrm{O}$ segundo efeito das medidas é o desincentivo à especulação pela apreciação do real, pois, ao taxar a formação de posições vendidas, o Governo inibe a formação de ciclos de apreciação originados no mercado de derivativos, conforme descrito acima. No entanto, por tabela, as medidas acertam também alguns agentes hedge do sistema, como os exportadores. Para fazer hedge de receitas futuras em dólares, os exportadores podem formar posições vendidas diretamente na BM\&F ou, alternativamente, podem recorrer ao sistema bancário através dos adiantamentos de

(38) Decreto 7.330, de outubro de 2010. Outras medidas complementares evitam que estrangeiros migrem recursos de outras aplicações ou tomem empréstimos para constituição dessas margens. A Resolução no 3.914 veda às instituições financeiras "a realização de aluguel, troca ou empréstimo de títulos, valores mobiliários e outro ativo financeiro para investidor não residente cujo objetivo seja o de realizar operações nos mercados de derivativos". A outra resolução do CMN, de n. 3.915, obriga a realização de operações de câmbio simultâneo "a todas as migrações internas de recursos em real destinados à constituição de margens de garantia, inicial ou adicional, realizadas por investidor não residente no país".

(39) Decreto 7.536. 
contratos de câmbio (ACC). No primeiro caso, o IOF incide diretamente sobre a empresa exportadora, já no segundo, os bancos que oferecem o ACC provavelmente vão cobrir posição, vendendo dólar futuro e, com isso, repassar o custo do IOF para o exportador.

Há, contudo, outras questões a serem consideradas acerca da taxação dos mercados de derivativos. Entre elas, está a consideração de que as medidas são inócuas, pois exportam o mercado de derivativos de câmbio para o exterior. No entanto, a análise realizada neste artigo não corrobora essa afirmação, uma vez que os impostos sobre derivativos serão transmitidos ao mercado offshore pela própria dinâmica do mercado.

Para tornar mais claro o argumento, vale retomar o exemplo que ilustra a forma de operação de um banco offshore: esse banco oferece um fundo com rendimento atrelado à moeda brasileira ou um contrato de NDF em reais a um cliente que fica vendido em dólares e comprado em reais enquanto o banco assume a ponta contrária. Logo, o cliente aufere diferencial de juros e ganha com a apreciação da moeda brasileira enquanto o banco paga o diferencial de juros e ganha com a depreciação do real. Para fazer hedge dessa operação, o banco recorre ao mercado onshore e vende dólares futuros na BM\&F. Contudo, ao se deparar com um imposto para tal operação, é natural que o banco repasse esse custo para seu cliente offshore, reduzindo a demanda por aplicações em reais. Nesse sentido, as medidas atingem os especuladores, tanto onshore quanto offshore.

Por fim, a taxação das operações de derivativos pode tornar a formação da taxa de câmbio do real menos sujeita aos ciclos especulativos. Ademais, ela pode gerar mudanças importantes na operacionalização do mercado de câmbio, como a transferência de operações do mercado de derivativos para o mercado à vista, assim como o aquecimento do mercado interbancário como instrumento de hedge para os bancos. Essas mudanças devem ser acompanhadas de perto pelo Governo, uma vez que podem tornar obsoletos aspectos regulatórios existentes e, mais importante, podem tornar necessárias novas medidas para o melhor funcionamento do mercado.

\section{Considerações finais}

Este artigo procurou se debruçar sobre o mercado de câmbio no Brasil e, a partir daí, analisar a operacionalidade da política cambial no País. Decorre dos argumentos colocados que a política cambial deve ser pensada de forma integrada, considerando os possíveis impactos em três níveis do mercado de câmbio (primário, interbancário e de derivativos) e como esses níveis se comunicam. Ou seja, uma política concebida e aplicada de forma isolada tendo em vista apenas uma parte do mercado de câmbio pode estar fadada a ser neutralizada dada a 
complexidade da dinâmica cambial no Brasil. Em particular, deve ser considerada, para análise e elaboração de políticas cambiais, a forma como essa impacta a formação de preços futuros nos canais de arbitragem e no desincentivo às operações especulativas nos mercados à vista e futuro.

\section{Referências bibliográficas}

AKYÜZ, Y.) Financial liberalization: the key issues. In: AKYÜZ, Y.; HELD, G. Finance and the real economy. Santiago: Univ. de las Naciones Unidas/CEPAL/UNCTAD, 1993. p. 19-68.

BIANCARELI, A. M. A abertura financeira no Brasil: um balanço crítico. In: MARCOLINO, L. C.; CARNEIRO, R. Sistema financeiro e desenvolvimento no Brasil. São Paulo: Atitude, 2010.

BCB. Posição de Câmbio dos Bancos. Boletim Focus, 2003.

BCB. Relatório de estabilidade financeira. set. 2010. Disponível em: http://www.bcb.gov.br/?RELESTAB201009.

BLUMENSCHEIN, F.; LEON, F. L. Uma análise do desempenho e da segmentação do sistema de crédito à exportação no Brasil. In: PINHEIRO, A. C. et al. O desafio das exportações. Rio de Janeiro: BNDES, 2002.

CARNEIRO, R. Globalização e inconversibilidade monetária, Revista de Economia Política, v. 28, n. 4 (112), p. 539-556, out./dez. 2008.

DODD, R.; GRIFFITH-JONES, S. Brazil's derivatives markets: hedging, Central Bank intervention and regulation. Economic Commission for Latin America and the Caribbean (ECLAC), 2007.

FARHI, M. Os impactos dos derivativos no Brasil. In: MARCOLINO, L. C.; CARNEIRO, R. Sistema financeiro e desenvolvimento no Brasil. São Paulo: Atitude, 2010.

FRANCO, G. The real plan and exchange rate. Essays international finance. Princeton University, 2000.

GAGNON, J. E.; CHABOUD, A. P. What can the data tell us about carry trades in Japanese yen? Board of Governors of the Federal Reserve System, Jul. 2007. (International Finance Discussion Papers, n. 899).

GARCIA, M. A macroeconomia do dólar futuro. Resenha $B M \& F, 118$, p. 37-45, 1997.

; URBAN, F. O mercado interbancário de câmbio. Rio de Janeiro: Pontifícia Universidade Católica do Rio de Janeiro, 2004.

HE, D.; McCAULEY, R. Offshore markets for the domestic currency: monetary and financial stability issues. BIS, 2010. (Working Papers, n. 320).

KALTENBRUNNER, A. International financialization and depreciation: the Brazilian Real in the International Financial Crisis. SOAS, 2010. 
KEYNES, J. M. (1924). A tract on monetary reform. New York: Prometheus Books, 2000. (1930). A treatise on money. In: THE COLLECTED writings of John Maynard Keynes. London: MacMillan, 1971. v. 5.

PRATES, D. M. Os determinantes das taxas de câmbio nominal e real no Brasil no período 2003-2007. In: FERREIRA, F.; MEIRELES, B. Ensaios sobre economia financeira. Rio de Janeiro: BNDES, 2009.

ROSSI, P. Taxa de câmbio no Brasil: dinâmicas da arbitragem e da especulação. Tese (Doutorado)-Instituto de Economia. Universidade Estadual de Campinas, Campinas, 2012.

; PRATES, D. M. Crédito à exportação. Projeto de estudos sobre as perspectivas da indústria financeira brasileira e o papel dos bancos públicos. Campinas, SP: IE-Unicamp / BNDES, 2009. Disponível em: http://www.iececon.net/arquivos/Financiamento_Exportacao.pdf.

SARNO, L.; TAYLOR, M. P. The economics of exchange rates. Cambridge: Cambridge University Press, 2006.

SOUZA, F. E. P.; HOFF, C. R. O regime cambial brasileiro: sete anos de flutuação. In: BERLINSKI, J. et al. (Org.). 15 Anos de Mercosur. Montevidéu: Editora Zonalibro, 2006.

VENTURA, A.; GARCIA, M. Mercados futuro e à vista de câmbio no Brasil: o rabo balança o cachorro. Rio de Janeiro: PUC, 2009. (Texto para discussão, n. 563). 